\title{
Competitividade da Produção de Palmito de Pupunha no Espírito Santo e em São Paulo
}

\author{
Eliane Pinheiro de Sousa ${ }^{1}$ \\ Naisy Silva Soares ${ }^{2}$ \\ Sidney Araujo Cordeiro ${ }^{3}$ \\ Márcio Lopes da Silva ${ }^{4}$
}

\begin{abstract}
Resumo: $\mathrm{O}$ presente trabalho tem como objetivo analisar a competitividade da produção de palmito de pupunha no Espírito Santo e em São Paulo por meio da Matriz de Análise Política (MAP). Os resultados mostram que as lucratividades privadas e sociais da produção e comercialização do palmito de pupunha são positivas em ambos os estados analisados e superiores às obtidas por culturas tradicionais, como a soja, e por produtos florestais, como a borracha natural. Entre esses estados, São Paulo apresenta maior lucratividade na produção de palmito, logo, é mais competitivo que o Espírito Santo. Entretanto, essas lucratividades poderiam ter sido maiores se produtores não tivessem sido penalizados por políticas públicas distorcivas.
\end{abstract}

Palavras-chave: Palmito de pupunha, Matriz de Análise Política, política florestal, Brasil.

Abstract: This work aims to analyze the competitiveness of pejibaye palm heart production in Espirito Santo and São Paulo states by applying the Policy Analysis Matrix (PAM). Results show that the private and social profitabilities of pejibaye palm heart production and trading were positive in both states and are higher than those obtained by traditional crops, such as soybean, and by forest products, such as natural rubber. São Paulo production was more profitable, being thus more competitive than Espirito Santo. However, these profitabilities could have been higher if producers were not exposed to negative effects of distorted public policies.

Key-words: Pejibaye palm heart, Political Analysis Matrix, forest policies, Brazil.

Classificação JEL: D61, Q28.

1 Doutora em Economia Aplicada pela Universidade Federal de Viçosa, Professora da Universidade Regional do Cariri (URCA) e Pesquisadora da FUNCAP. E - mail: pinheiroeliane@hotmail.com

2 Doutora em Ciência Florestal pela Universidade Federal de Viçosa (UFV) e Professora da Universidade Estadual de Santa Cruz (UESC). E - mail: naisysilva@yahoo.com.br

3 Doutor em Ciência Florestal pela Universidade Federal de Viçosa (UFV) e Professor da Universidade Federal do Piauí (UFPI).E -mail: sidneyufv@com.br

4 Doutor em Ciência Florestal pela Universidade Federal de Viçosa e Professor da Universidade Federal de Viçosa (UFV).E -mail: marlosil@ufv.br 


\section{Introdução}

A pupunha (Bactris gasipaes Kunth.) é uma palmeira originária da região Amazônica, tendo sido domesticada e disseminada nesta região e na América Central por povos indígenas. É uma ótima alternativa para produção de palmito, podendo ser explorada em plantios comerciais, tendo ainda características desejáveis, como precocidade, perfilhamento, rendimento e qualidade do seu palmito (CHAIMSOHN, 2000).

O cultivo da pupunheira para produção de palmito vem despertando, desde a década de 70, o interesse de agricultores de todo o País. Esse interesse é devido, principalmente, à demanda elevada, tanto interna quanto externa, de palmito de boa qualidade, e à alta lucratividade do setor. A busca de novas opções de cultivo em substituição às tradicionais, em virtude dos baixos preços alcançados por esses últimos no mercado, faz também com que empresários de outros setores se aventurem no agronegócio do palmito de pupunha (BOVI, 2000).

O Brasil é o maior produtor e consumidor de palmito do mundo, mas não possui mais o título de maior exportador. Nos últimos anos, a Costa Rica e o Equador, com plantios comerciais de pupunha e ganhos em escala e, consequentemente, preços mais baixos, assumiram a liderança do mercado internacional. A perda do Brasil da primeira posição no ranking dos maiores exportadores mundiais deve-se ao fato de o palmito nacional apresentar baixa qualidade e ser um produto não ecológico, pois é sustentado pelo corte de palmeiras nativas. A baixa qualidade do palmito é resultado do processo de extrativismo (GUERREIRO, 2002; SAMPAIO et al., 2007).

Devido ao potencial comercial do palmito de pupunha, muitos países latino-americanos estão investindo no seu cultivo e industrialização. $\mathrm{O}$ interesse no cultivo da pupunha vem aumentando fortemente nos últimos anos (VILLACHICA, 1996), especialmente para a produção de palmito. Dois fatores estão facilitando este aumento: a existência de um mercado mundial e a disponibilidade de tecnologia para o cultivo e industrialização da pupunha para palmito (VERRUMA-BERNARDI, 2007).

Em 2008, o Brasil exportou 1.624 toneladas de palmito, com receita de US\$ 7,1 milhões, e a maior parte desses embarques foi destinada aos Estados Unidos, com 1.072 toneladas (66\% do total dos envios), seguido pela França, com 133 toneladas (AGRIANUAL, 2009).

A produção de palmito no Brasil em 2007 foi de 61.429 toneladas, o que representa uma área colhida de 10.035 hectares. As regióes Centro-Oeste e Nordeste são responsáveis por 78,5\% dessa produção. Os estados de Goiás e Bahia se destacam nessas regiões e também em termos nacionais, com produção de 23.092 e 21.253 toneladas, respectivamente. Outros estados, como Espírito Santo e São Paulo, áreas de interesse deste trabalho, apesar de apresentarem 
produção modesta, 778 e 1.933 toneladas, em 2007, respectivamente, em comparação com Goiás e Bahia, estão se destacando em termos nacionais, em relação à evolução de área colhida, quantidade produzida e rendimento médio por hectare (IBGE, 2007).

Em 2008, a produção de palmito passou para 84.006 toneladas, com área colhida de 13.393 ha. Esse crescimento da área foi apropriado quase totalmente por São Paulo, que passou a ter produção de 17.274 toneladas, o que corresponde a $82,27 \%$ do total da região Sudeste e a 20,56\% do nacional. Entre 2007 e 2008, São Paulo teve acréscimo de 795,6\% na área colhida. Espírito Santo e Goiás tiveram aumento de $2,47 \%$ e $0,57 \%$, respectivamente, enquanto a Bahia teve queda de 1,31\% (IBGE, 2007 e 2008).

A tendência do mercado de palmito de pupunha é crescente tanto no mercado interno como externo. Isso ocorre não somente para atender às exigências do mercado internacional, como pela atual demanda dos frutos de açaí. Os frutos do açaizeiro (Euterpe oleracea Mart.) vêm sendo usados para a produção de polpas de frutas, sorvetes, licores, doces, néctares e geleias, bem como para a extração de corantes e antocianina, que apresentam maior rentabilidade que o mercado de palmito, apontando, assim, para uma diminuição paulatina deste palmito no mercado. Além disso, é importante destacar que, no cultivo da pupunha, é possível colher o palmito a partir dos dois anos de idade e, a partir desta idade, têm-se cortes anuais, o que não ocorre com o palmito juçara (Euterpe Edulis), por exemplo, que demora aproximadamente sete anos para alcançar tamanho comercial no Brasil. Além disso, somente a partir desta idade é que se têm cortes a cada três ou quatro anos. Esta vantagem do palmito de pupunha também se estende em relação ao palmito de açaí, cujo ciclo de corte varia em média de cinco em cinco anos (CHAIMSOHN, 2000).

O esgotamento da oferta de matéria-prima proveniente da coleta extrativa no Centro-Sul, a intensificação da fiscalização de órgãos oficiais impedindo a devastação predatória, o custo da taxa de reflorestamento (próximo de $12 \%$ dos custos de industrialização), o elevado preço do produto nos mercados nacional e internacional, sendo que, no primeiro, a tonelada do produto líquido drenado é vendida a preços acima de US\$ 4.000,00, são fatores que têm estimulado o investimento e a produção racional para palmito industrializado (VERRUMABERNARDI, 2007).

Entretanto, existem alguns entraves ao cultivo das palmeiras inerentes à planta, que desestimulam o cultivo em larga escala das principais palmeiras produtoras de palmito comestível de boa qualidade. Palmeiras do gênero Eutepe demoram de 8 a 12 anos para estarem aptas para o corte do palmito. $\mathrm{O}$ segundo fator de importância é a baixa sobrevivência das mudas, especialmente da palmeira juçara, com perdas às vezes superiores a 40\%. Em terceiro lugar, pode ser mencionada a heterogeneidade do material existente. Como espécies 
que sofreram pouco melhoramento, há grande variabilidade entre e dentro das populações, o que se traduz em ausência de uniformidade na formação das mudas, na área de cultivo e na colheita do produto. Há variabilidade também para características químicas e bioquímicas do palmito, afetando sobremaneira a qualidade do produto final. Perda rápida da viabilidade das sementes e dificuldade para sua conservação e armazenamento são outros fatores que, se não impedem, pelo menos prejudicam o plantio único em largas áreas (GUERREIRO, 2002). Além disso, acredita-se que políticas públicas também estejam prejudicando o cultivo de palmeiras no Brasil e, consequentemente, a geração de emprego, renda e divisas no País.

Sendo assim, estudos mostrando os efeitos das políticas públicas na produção de palmito tornam-se relevantes, pois permitem identificar pontos de estrangulamento na estrutura de custos do setor produtivo para que se possam direcionar políticas que objetivem a manutenção e/ou a ampliação da capacidade produtiva e de exportação de palmito do Brasil. Estudos deste tipo podem, também, explicar os impactos de políticas públicas no setor, o que subsidiaria a adoção de medidas políticas, contribuindo para a tomada de decisão de alocação dos recursos e do planejamento de políticas comerciais.

Diante do exposto, o presente trabalho tem como objetivo geral analisar a competitividade da produção de palmito de pupunha no Brasil, comparando diferentes regiões do Brasil: São Paulo e Espírito Santo. Especificamente, pretende-se determinar a lucratividade privada e social na produção do palmito de pupunha no Brasil para as diferentes regiões; identificar os efeitos de políticas públicas sobre essas regiões, em relação ao mercado externo; mensurar os indicadores que avaliam o grau de competitividade do setor produtivo, assim como a eficiência econômica e os efeitos das políticas neste setor, levando em consideração os resultados privados e sociais; analisar a sensibilidade dos indicadores privados e sociais devido a uma variação nos preços sociais; e propor medidas para o desenvolvimento do setor no Brasil.

\section{Metodologia}

\subsection{Referencial Teórico}

O fundamento teórico deste trabalho se baseou na abordagem que relaciona a competitividade aos custos. Nesse contexto, Rosado (1997) ressalta que o conhecimento dos componentes dos custos é útil para a compreensão da competitividade. Segundo a autora, a competitividade resulta da interação entre os custos de produção e todos os custos adicionais incorridos para que o produto seja comercializado para o comprador estrangeiro. Assim, para determinar a competitividade, é necessário considerar os fatores e os efeitos de políticas que influenciam os preços enfrentados pelos agentes econômicos. Esses 
determinantes incluem eficiência produtiva, política de preços dos insumos, taxa de juros, taxa de câmbio e política de impostos e subsídios.

O conceito de eficiência associa a competitividade de uma economia às condições gerais do processo de produção. Nesse sentido, o progresso tecnológico é um elemento central na configuração e na evolução dos sistemas econômicos e dos fluxos internacionais de comércio, assim como o melhor aproveitamento de economias de escala, maior capacitação de mão de obra etc. (HAGUENAUER, 1989; ALVES, 2002). Os indicadores de eficiência relacionam-se com a comparação dos preços e custos unitários de um país com os de um determinado conjunto de competidores internacionais (IE/UNICAMP et al., 1993).

Além disso, também é relevante mencionar que os insumos comercializados internacionalmente estão sujeitos a impostos, tarifas ou subsídios que podem gerar distorções consideráveis sobre a competitividade (FERREIRA NETO, 2005).

Em geral, a competitividade resulta da combinação dos efeitos de distorções de mercado, que incluem aquelas causadas por política econômica e por competição imperfeita entre as firmas e de vantagens comparativas (ALVIM e OLIVEIRA JÚNIOR, 2005).

Feitas essas considerações, verifica-se que a competitividade é influenciada por uma grande quantidade de fatores inter-relacionados, como tecnologia disponível e a forma como ela é aplicada, preços domésticos dos insumos produtivos, taxa de câmbio, taxa de paridade entre os parceiros comerciais do país, custos de transporte, estrutura de incentivos, barreiras tarifárias e não tarifárias no país importador, qualidade e imagem do produto etc. (BNDES, 1991, citado por FERREIRA NETO, 2005).

\subsection{Referencial Analítico}

\subsubsection{Considerações Preliminares}

Para atender aos objetivos deste trabalho, empregou-se o método da Matriz de Análise Política (MAP), desenvolvido por Monke e Pearson (1989).

Esse instrumental permite identificar incentivos ou desincentivos para agentes econômicos; analisar o impacto de políticas diretas em nível de cadeia; verificar os efeitos de políticas sobre a lucratividade privada e examinar os impactos favoráveis ou desfavoráveis à sociedade relativos às atividades econômicas (ALVES, 2002). Desta forma, este método é frequentemente utilizado na análise da cadeia produtiva de produtos da agropecuária no Brasil e no exterior (NELSON, 1991; NELSON e PANGGABEAN, 1991; ROSADO, 1997; AHMAD e MARTINI, 2000; MARRA et al., 2001; MARTINS, 2001; ALVES, 2002; MOHANTY et al., 2002; ALVIM et al., 2004; ALVIM e OLIVEIRA JÚNIOR, 2005; FERREIRA NETO, 2005; MOSS, 2006; ROSADO et al., 2006). 
Na literatura econômica internacional, a MAP foi empregada na área florestal nos estudos de Maryani e Irawanti (1997), Hadi e Budhi (1997) e Endom (1999). Maryani e Irawanti (1997) analisaram os impactos das políticas públicas na competitividade da produção de óleo de palma e da madeira industrial processada em Sumatra, Indonésia, mais precisamente, na província de Riau, em 1997, que é constituída por seis distritos. São eles: Pakan Baru, Kampar, Bengkalis, Inderagiri Hulu, Kepulauan Riau e Batam. Os autores concluíram que tanto a produção de óleo de palma quanto a produção de madeira industrial processada são economicamente eficientes devido às políticas governamentais para essas mercadorias.

Hadi e Budhi (1997) estudaram a eficiência econômica e a vantagem comparativa dos pequenos produtores de borracha natural de Sumatra, Indonésia, em 1997, considerando-se o sistema agroflorestal e a monocultura. Os autores constataram que os dois sistemas de produção não foram competitivos e que, no sistema agroflorestal, as perdas são maiores que no sistema de monocultura para os pequenos produtores.

Já o estudo de Endom (1999) verificou os impactos das políticas públicas na competitividade da indústria de madeira na província de Jambi, distrito de Bungo Tebo, em Kabupaten, Indonésia, em 1997. As regiões que compuseram a amostra foram: PT Rimba Karya Indah, PT Dalek Esa Hutani, PT Gaya Wahana Timber, e PT Sylvagama. Os resultados revelaram que a indústria da madeira na Indonésia, que opera em larga escala, é relativamente competitiva e tem elevada eficiência. No entanto, as políticas públicas contribuíram para que o preço da tora no mercado doméstico ficasse menor que o valor internacional.

Em relação à literatura econômica nacional, encontrou-se apenas o estudo de Rosado et al. (2006), que utilizou a MAP na área florestal. Esse trabalho buscou analisar a competitividade e os efeitos das políticas públicas sobre a produção da borracha natural nos estados de São Paulo e Mato Grosso. Os autores constataram que a produção da borracha natural nesses estados está sendo prejudicada pelas políticas públicas, mas, apesar disso, é lucrativa e competitiva. Desta forma, tendo em vista que estudos que contemplam o emprego da MAP em produtos florestais têm sido tão pouco explorados e dada sua relevância, este estudo pretende contribuir neste sentido.

\subsubsection{Operacionalização do Modelo}

AMAP expressa alucratividade definida como a diferença entre receitas ecustos e mensura o efeito das divergências (políticas "distorcivas" e falhas de mercado), sendo a diferença entre os valores privados e valores sociais. Ela é constituída por duas colunas de custos, uma referente aos insumos comercializáveis (tradeable) e outra relativa aos fatores domésticos (nontradeable). Por sua vez, os insumos intermediários (fertilizantes, pesticidas, sementes, rações, eletricidade, transporte 
e combustível) são divididos em seus componentes de insumos comercializáveis e não comercializáveis, conforme indicado na Tabela 1.

Tabela 1. Matriz de Análise Política (MAP)

\begin{tabular}{|c|c|c|c|c|}
\hline \multirow[b]{2}{*}{ Itens } & \multirow[b]{2}{*}{ Receitas } & \multicolumn{2}{|c|}{ Custos } & \multirow[b]{2}{*}{ Lucros } \\
\hline & & $\begin{array}{c}\text { Insumos } \\
\text { Comercializáveis }\end{array}$ & $\begin{array}{c}\text { Fatores } \\
\text { Domésticos }\end{array}$ & \\
\hline Preços Privados & A & B & $\mathrm{C}$ & $\mathrm{D}$ \\
\hline Preços Sociais & E & F & G & $\mathrm{H}$ \\
\hline $\begin{array}{l}\text { Efeitos de divergências e } \\
\text { eficiência política }\end{array}$ & I & $\mathrm{J}$ & K & $\mathrm{L}$ \\
\hline
\end{tabular}

Fonte: Monke e Pearson (1989).

A manipulação dos valores contidos na MAP origina os seguintes indicadores:

a) Lucro Privado (D): O lucro privado é representado pela diferença entre a receita obtida no mercado interno e seus custos, sendo expresso a preços de mercado, ou a preços privados (eq. 1). Como valores praticados no mercado, eles sofrem interferências dos governos, na forma de tributos ou subsídios.

$$
D=A-B-C
$$

em que: $A=p^{d} q^{d} ; B=\sum_{i=1}^{n} p_{i}^{d} q_{i}^{d}$ e $C=\sum_{j=1}^{n} w_{j}^{d} 1_{j}^{d}$.

Sendo $A=$ receita privada, $B=$ custo dos insumos comercializáveis externamente, $C=$ o custo dos insumos domésticos, $p^{d}=$ preço privado do produto, $q^{d}=$ quantidade total privada de determinado produto: $p_{i}^{d}=$ preço privado do insumo i, $q_{i}^{d}=$ quantidade privada do insumo i utilizado na produção do bem considerado, $w_{j}^{d}=$ preço privado do insumo $\mathrm{j}, 1_{j}^{d}=$ quantidade privada do insumo j utilizado. Os subscritos " $\mathrm{i}$ " $\mathrm{e}$ " $\mathrm{j}$ " indicam, respectivamente, insumo comercializável externamente e insumo doméstico. Ademais, n representa o número de insumos comercializáveis considerados em B e o número de insumos não comercializáveis incluídos em C.

O cálculo da lucratividade privada retrata a competitividade da cadeia produtiva, de modo que se os lucros privados forem negativos $(D<0)$, os operadores estarão ganhando uma taxa de retorno subnormal; e se os lucros privados forem positivos ( $\mathrm{D}>0$ ), os operadores estarão ganhando uma taxa de retorno sobrenormal, sinalizando que pode ocorrer expansão do sistema de produção em análise no futuro. O lucro normal ocorre se $\mathrm{D}=0$ (ROSADO et al., 2006).

b) Lucro Social (H): Refere-se ao lucro alcançado a preços de sociais (eq. 2).

$$
H=E-F-G
$$

em que: $E=p^{s} q^{s} ; F=\sum_{i=1}^{n} p_{i}^{s} q_{i}^{s}$ e $G=\sum_{i=1}^{n} w_{j}^{s} 1_{j}^{s}$. 
Sendo $E=$ receita social, $F=$ custo dos insumos comercializáveis, $G=$ custo dos insumos domésticos, $p^{s}=$ preço social do produto, $q^{s}=$ quantidade total do produto, $p_{i}^{s}=$ preço social do insumo $\mathrm{i}, q_{i}^{s}=$ quantidade do insumo i utilizado, $w_{j}^{s}=$ preço social do insumo $\mathrm{j}, 1_{j}^{s}=$ quantidade do insumo $\mathrm{j}$ utilizado.

Esses valores não sofrem interferências de governos. Assim, são considerados valores sociais ou econômicos e medem a eficiência do sistema de produção. Como medida de eficiência ou vantagem comparativa, o lucro social, quando negativo, indica que o sistema não é considerado economicamente viável no contexto de mercado internacional, sem assistência do governo. Tem-se a indicação de que tal sistema não assegura a alocação economicamente eficiente de recursos escassos, dado que produz a custos sociais superiores aos custos de importação (ALVES, 2002; VIEIRA et al., 2001).

c) Efeitos das divergências e da eficiência política: Correspondem às diferenças entre as avaliações privadas e sociais de receitas, custos e lucros, que devem ser explicadas pelos efeitos da distorção política ou pelas imperfeições nos mercados de produtos e fatores. A mensuração desses efeitos das divergências e da eficiência política pode ser expressa pelas eq. 3 a 6 :

Transferência de receitas: $I=A-E$

Transferência de insumos: $J=B-F$

Transferência de fatores: $K=C-G$

Transferência líquida: $L=D-H$ ou $L=I-J-K$

As transferências de receitas estão associadas à produção, e as transferências de insumos estão associadas aos custos de insumos comercializáveis, que resultam de políticas que causam divergências entre os preços domésticos dos produtos e os preços internacionais, como políticas específicas de produtos (taxas ou subsídios) e política cambial. Por fim, os preços dos produtos e de fatores também podem ser influenciados pelas falhas de mercado, devido a informações imperfeitas ou ao desenvolvimento ineficiente das instituições que consistem em características do funcionamento de mercados. As transferências líquidas combinam efeitos de políticas "distorcivas" com aqueles provenientes de falhas de mercado de fator e políticas eficientes para compensá-los (ALVES, 2002).

A comparação entre sistemas de produção que geram bens idênticos foi feita pelos indicadores a seguir (FERREIRA NETO, 2005; MOSS, 2006; ROSADO et al., 2006):

a) Razão do Custo Privado (RCP): A RCP mostra quanto o sistema pode pagar pelos fatores domésticos, permanecendo competitivo, ou seja, equilibrando a receita com a despesa (sem lucro nem perda) após alcançar lucros normais. Para que o produtor alcance este objetivo, é necessário que os custos de seus fatores 
domésticos sejam menores que seus valores adicionais (diferença entre receita e custos dos insumos comercializáveis), a preços privados. Deste modo, segundo Moss (2006), para a maximização dos lucros, é indispensável a minimização desta razão por meio do controle dos custos dos fatores domésticos.

Essa razão é calculada como apresentada na eq. 7.

$$
R C P i=i C i / i(A i-i B)
$$

A RCP pode indicar se os fatores domésticos estão recebendo o seu retorno normal $(\mathrm{RCP}=1)$, acima do retorno normal $(\mathrm{RCP}<1)$ ou abaixo do retorno normal $(\mathrm{RCP}>1)$.

b) Custo dos Recursos Domésticos (CRD): O custo dos recursos domésticos (CRD) é uma medida de vantagem comparativa mais criteriosa que a lucratividade social. Indica o comportamento da lucratividade social, ou seja, quanto se despende de recursos domésticos em valores sociais para gerar uma unidade de divisas por meio da exportação (eq. 8).

$$
C R D i=i G i / i(E i-i F)
$$

Minimizar o CRD é equivalente a maximizar os lucros sociais. O CRD $<1$ significa que se estaria utilizando menos de um dólar de recursos domésticos para gerar um dólar de divisas e vice-versa. Indica, também, eficiência da produção.

c) Coeficiente de Proteção Nominal (CPN): O coeficiente de proteção nominal (CPN) indica o impacto da política que provoca divergências entre preços privados e sociais. É a razão entre os preços privados e sociais (eq. 9) (FERREIRA NETO, 2005).

$$
C P N i=i A i / i E
$$

Tem-se o CPN sobre produtos comercializáveis $(\mathrm{CPNp})$ e sobre os insumos comercializáveis (CNPi) (equação 10 e 11, respectivamente).

$$
\begin{aligned}
& C P N p=A / E \\
& C P N i=B / F
\end{aligned}
$$

Se o CPNp $>1$ indica que existe transferência de renda da sociedade para os produtores e vice-versa, o CPNi $>1$ sinaliza que há transferência de renda negativa aos produtores, pois os custos dos insumos comercializáveis são aumentados pela política e vice-versa (ROSADO et al., 2006).

d) Coeficiente de Proteção Efetiva (CPE): O Coeficiente de Proteção Efetiva (CPE) é importante, pois permite indicar a extensão dos incentivos ou do desestímulo que os sistemas produtivos recebem das políticas de preços de produtos e de insumos comercializáveis. Quando o CPE $>1$, os lucros 
privados são maiores do que aqueles isentos de políticas dos produtos e insumos comercializáveis conjuntamente, ou seja, o efeito líquido das políticas contribui para um aumento do lucro privado e vice-versa. O CPE é obtido pela razão das diferenças entre receitas e custos comercializáveis (eq. 12) (ROSADO et al., 2006).

$$
C P E=(A-B) /(E-F)
$$

e) Coeficiente de Lucratividade (CL): O Coeficiente de Lucratividade (CL) mede o efeito dos incentivos de todas as políticas. É obtido pela razão entre lucros privados e sociais (eq. 13) (FERREIRA NETO, 2005).

$$
C L=(A-B-C) /(E-F-G)=D / H
$$

f) Taxa de Subsídios aos Produtores (TSP): A Taxa de Subsídios aos Produtores (TSP) mostra a proporção de renda, em valores sociais, que seria requerida para manter a eficiência econômica se um subsídio ou imposto fosse substituído por um conjunto de políticas de outra natureza. É uma medida da transferência líquida de políticas (L) como uma proporção das receitas sociais totais (E) (equação 14). Quanto menor a TSP, menos distorcido será o sistema (FERREIRA NETO, 2005).

$$
T S P=i L i / i E i=i(D i-i H) i / E
$$

\subsubsection{Fonte de dados}

Os preços do palmito no estado de São Paulo foram obtidos no IEA (Instituto de Economia Agrícola) (IEA, 2009) e os preços do palmito no estado do Espírito Santo são provenientes do banco de dados agregados do IBGE (Instituto Brasileiro de Geografia e Estatística) (IBGE, 2009). O preço social foi obtido no estudo de Chaimsohn (2006) e corresponde ao preço praticado na Costa Rica, um grande produtor e exportador de palmito, conforme observou Merecí (2008). Tais preços privados e sociais do palmito são referentes a agosto de 2006.

Os preços privados dos insumos comercializáveis e dos fatores de produção empregados em São Paulo foram extraídos do Agrianual (Anuário Estatístico da Agricultura Brasileira) (AGRIANUAL, 2008), enquanto os utilizados no Espírito Santo foram obtidos do Cedagro (Centro de Desenvolvimento do Agronegócio) (CEDAGRO, 2008). Esses preços são referentes à média de 2007.

Os preços sociais dos insumos comercializáveis e dos fatores de produção foram obtidos no estudo de Chaimsohn (2006), referentes aos preços da Costa Rica, e no site do Ministerio de Agricultura Ganadería, Acuacultura Y Pesca del Ecuador, mais precisamente no Servicio de Información y Censo Agropecuario (SICA, 2009), referentes aos preços praticados no Equador. Tais valores correspondem a agosto de 2006 . 
De acordo com Moss (2006), os preços sociais dos insumos e o valor social do produto são os próprios preços internacionais.

Para o cálculo dos custos, adotou-se um horizonte temporal de dois anos. Isso significa que os valores de cada insumo comercializável e fator de produção foram obtidos pelo produto dos preços médios unitários referentes a 2007 e das quantidades requeridas de dois períodos ( $1^{\mathrm{o}}$ e $2^{\underline{0}}$ anos). Essa adoção de dois anos na mensuração dos custos foi baseada no ciclo produtivo do palmito de pupunha, que, conforme Chaimsohn (2000), pode ser colhido a partir de dois anos de idade.

Os preços dos insumos e do palmito no exterior foram internalizados no Brasil, multiplicando-os pela taxa de câmbio do período a que se referiam. Em seguida, os preços internos foram corrigidos pelo Índice Geral de Preços - Disponibilidade Interna (IGP-DI) do Ipea (Instituto de Pesquisa Econômica Aplicada) (IPEADATA, 2009). Assim, os preços utilizados para cálculo dos indicadores estão em reais, de março de 2009.

Não se trabalhou com mais regiões porque alguns dados não estavam disponíveis e, por entender que apesar de Espírito Santo e São Paulo não serem as regiões com maior produção no Brasil, são áreas que possuem grande potencial para o desenvolvimento da cultura no País.

\section{Resultados e discussão}

Neste tópico são apresentados os resultados dos indicadores estimados pela MAP para o setor produtivo do palmito de pupunha em São Paulo e no Espírito Santo.

Inicialmente, é apresentada uma discussão sobre as lucratividades privadas e sociais e, posteriormente, as transferências financeiras e os indicadores privados e sociais. O último item refere-se à análise de sensibilidade dos indicadores privados e sociais em razão de uma variação nos preços sociais.

\subsection{Lucratividades privadas e sociais}

Os resultados da MAP, considerando-se a produção de palmito de pupunha no Espírito Santo e em São Paulo, são mostrados no Quadro 2.

Os resultados obtidos evidenciam que a lucratividade privada da produção e comercialização do palmito de pupunha para o mercado interno no setor produtivo foi positiva, com valores de R\$2,12 e R\$2,44 por quilo, no Espírito Santo e em São Paulo, respectivamente (Quadro 2). Em outras palavras, os estados sob análise são competitivos na produção do palmito de pupunha. Considerando-se que no segundo ano de cultivo a produtividade média seja de 800 quilos por hectare no Espírito Santo e de 3.500 quilos por hectare em São Paulo, conforme dados obtidos, respectivamente, no Cedagro (2008) e Agrianual 
(2008), as lucratividades nesses estados foram, respectivamente, de $\mathrm{R} \$ 1.696,00 \mathrm{e}$ $\mathrm{R} \$ 8.540,00$ por hectare, em março de 2009.

Em termos comparativos com a lucratividade obtida em reais por hectare por ano de produtos tradicionais como a soja, e de produtos florestais como a borracha natural, verifica-se que a lucratividade na produção de palmito de pupunha é muito alta nos dois estados considerados neste estudo. Essa evidência é constatada quando se compara com os resultados obtidos por Alvim e Oliveira Júnior (2005), que encontraram lucratividade de R \$285,95 e R \$553,01 na produção de soja por hectare na safra de 2004/2005 em Mato Grosso do Sul, para os sistemas de plantio convencional e de plantio direto, respectivamente. Ao se comparar com a borracha natural, também se observa que o palmito de pupunha é muito mais lucrativo, visto que Rosado et al. (2006) obtiveram lucratividade por hectare de $\mathrm{R} \$ 137,39$ e $\mathrm{R} \$ 72,00$, respectivamente, em São Paulo e Mato Grosso, para a produção de borracha natural em 2002.

As lucratividades sociais nos estados do Espírito Santo e São Paulo foram de $\mathrm{R} \$ 3,52 / \mathrm{kg}$ e $\mathrm{R} \$ 5,87 / \mathrm{kg}$, respectivamente, indicando que há eficiência econômica na produção do palmito de pupunha nesses estados brasileiros (Tabela 2). Os resultados demonstram que a produção dessa cultura desempenha papel relevante na alocação de recursos nacionais e na geração de divisas. De acordo com o Centro de Inteligência em Florestas (CI Florestas, 2010), os produtos não madeireiros que se destacam na pauta de exportações brasileiras são: castanha-do-pará, palmito (em conserva), óleo essencial de eucalipto e taninos. Dentre esses produtos, dados do Ministério do Desenvolvimento, Indústria e Comércio Exterior (MDIC, 2010) mostram que o palmito foi responsável por $31,87 \%$ da receita obtida com as exportações em 2007, perfazendo US\$ 13.765.135.

Tabela 2. Matriz de Análise Política para o palmito de pupunha no Espírito Santo e São Paulo, março de 2009.

\begin{tabular}{|c|c|c|c|c|}
\hline \multirow{2}{*}{$\begin{array}{c}\text { Sistemas } \\
\text { Tecnológicos }\end{array}$} & \multirow{2}{*}{$\begin{array}{c}\text { Receita }(\mathrm{R} \$ / \\
\mathrm{kg})\end{array}$} & \multicolumn{2}{|c|}{ Custos de Comercialização ( $\mathrm{R} \$ / \mathbf{k g})$} & \multirow{2}{*}{$\begin{array}{c}\text { Lucro/ } \\
\text { Benefício } \\
\text { Social }(\mathrm{R} \$ / \mathbf{k g})\end{array}$} \\
\hline & & $\begin{array}{c}\text { Insumos } \\
\text { Comercializáveis } \\
\end{array}$ & $\begin{array}{c}\text { Fatores } \\
\text { Domésticos }\end{array}$ & \\
\hline \multicolumn{5}{|l|}{ Espírito Santo } \\
\hline Preços Privados & 9,50 & 5,44 & 1,94 & 2,12 \\
\hline Valorações Sociais & 10,10 & 4,86 & 1,72 & 3,52 \\
\hline$\underline{\text { Efeitos de Divergências }}$ & $-0,60$ & 0,58 & 0,22 & $-1,40$ \\
\hline \multicolumn{5}{|l|}{ São Paulo } \\
\hline Preços Privados & 7,70 & 3,98 & 1,28 & 2,44 \\
\hline Valorações Sociais & 10,10 & 3,13 & 1,10 & 5,87 \\
\hline Efeitos de Divergências & $-2,40$ & 0,85 & 0,18 & $-3,43$ \\
\hline
\end{tabular}

Fonte: Dados da Pesquisa. 
Em termos comparativos, a produção do palmito de pupunha em São Paulo apresentou maior lucratividade privada e social, mostrando a eficiência e a maior competitividade desse estado. A maior lucratividade de São Paulo pode ser explicada pelo maior rendimento em relação ao Espírito Santo. Em 2007, por exemplo, o rendimento médio da produção do palmito de pupunha em São Paulo foi de 5.007 kg/ha e, no Espírito Santo, de $1.011 \mathrm{~kg} / \mathrm{ha}$ (IBGE, 2007). Entretanto, as diferenças de lucratividade entre os dois estados não estão associadas exclusivamente aos diferenciais de produtividade, mas também aos distintos custos de comercialização.

Conforme se verifica a partir da MAP, os dispêndios com insumos comercializáveis e fatores domésticos são, respectivamente, 26,84\% e 34,02\% menores em São Paulo se comparados com os verificados no Espírito Santo. No caso dos insumos comercializáveis, os itens responsáveis por essa distinção de valores foram as mudas para plantio e replantio do palmito. Os fatores domésticos que apresentaram preços inferiores em São Paulo em relação ao Espírito Santo foram marcação de cova, adubação nas covas, plantio e replantio, capina manual nas linhas, roçagem manual nas entrelinhas e adubação de cobertura.

Pode-se dizer, ainda, que os lucros privados foram inferiores aos sociais tanto no Espírito Santo quanto em São Paulo. Isso pode ser devido à ineficiência de políticas públicas implementadas, ou seja, à ineficiência das políticas públicas na tributação, na taxa de câmbio, nos encargos sociais e nas políticas comerciais.

Conforme observaram Rezende et al. (2005) e Delepinasse e Bonse (2002), são vários os tributos que incidem sobre o setor florestal brasileiro. As principais taxas, contribuições sociais e impostos que incidem sobre a produção do palmito no país são: Contribuição Social sobre o Lucro (CSL), Contribuição para Financiamento da Seguridade Social (Cofins), Contribuição para o Instituto Nacional de Seguridade Social (INSS), Contribuição para o Programa de Integração Social (PIS), Contribuição Sindical Rural (CSR), Imposto Territorial Rural (ITR), Imposto sobre Circulação de Mercadorias e Serviços (ICMS) e Imposto Renda sobre pessoa jurídica (IRPJ) e imposto sobre produtos industrializados (IPI).

Em 2009, a CSL, Cofins e PIS foram de 1,08\%, 3\% e 0,65\% sobre o valor presente das receitas (VPR), respectivamente. O INSS foi de $6 \%$ sobre o Valor Presente dos Custos (VPC), sem tributos. O IRPJ foi 15\% sobre o Valor Presente Líquido (VPL). Já a alíquota de importação dos adubos e fertilizantes variou de $4 \%$ a $6 \%$ na Tarifa Externa Comum (TEC). A alíquota do IPI foi de 10\% (MINISTÉRIO DO DESENVOLVIMENTO INDÚSTRIA E COMÉRCIO - MDIC, 2010; DELEPINASSE e BONSE, 2002; REZENDE et al., 2005, STCP ENGENHARIA DE PROJETOS, 2010).

As políticas públicas, como o Programa de Apoio ao Agroextrativismo, para o segmento de produtos florestais não madeireiros beneficiaram a produção na região norte do Brasil (PNUD BRA/99/025). Além disso, no País existem políticas 
específicas para alguns produtos, como a borracha natural, açaí e dendê. Dentre estas políticas, podem-se citar políticas de preços mínimos e de subsídio à produção. Entretanto, no presente trabalho, no período analisado, não foi constatada uma política específica para a produção do palmito. Isso também pode explicar a baixa lucratividade da produção de palmito em SP e ES.

\subsection{Transferências financeiras associadas ao preço do produto}

Os resultados da MAP para o setor produtivo do palmito de pupunha mostraram que os valores privados são menores que os valores sociais, o que evidencia uma transferência negativa de $R \$ 0,60 / \mathrm{kg}$ no Espírito Santo e de R\$ 2,40/kg em São Paulo. Assim, pode-se inferir que os produtores desses dois estados foram penalizados por políticas distorcivas como política de juros, política cambial, tributária e comercial, dado que essa atividade recebeu menos do que receberia se essas políticas não tivessem sido implantadas. Em outras palavras, produtores poderiam ter alcançado níveis maiores de lucratividade, caso não tivessem sido penalizados por políticas distorcivas. Mas, mesmo assim, verificouse que a produção no Espírito Santo e em São Paulo é lucrativa (Tabela 2).

Ressalta-se também que, como os preços internos estão menores que os internacionais, pode-se dizer que ocorreu uma transferência de renda de produtores para a sociedade.

\subsection{Transferências financeiras associadas a preços dos insumos}

Segundo dados da Tabela 2, os valores encontrados para as transferências associadas aos custos dos insumos comercializáveis foram $R \$ 0,58 / \mathrm{kg}$ e $R$ \$ 0,85/ $\mathrm{kg}$ no Espírito Santo e em São Paulo, respectivamente.

Como se trata de insumos comercializáveis, pode-se dizer que os efeitos de divergências entre os valores privados e sociais são atribuídos às políticas distorcivas e não às imperfeições do mercado. Essas políticas distorcivas fazem com que exista divergência entre os preços no mercado nacional e internacional. O impacto do ICMS (Imposto sobre Circulação de Mercadorias e Serviços) é um exemplo desse tipo de política distorciva.

Acredita-se que se o governo não tivesse taxado o preço dos insumos comercializáveis, os custos de produção do palmito de pupunha nos estados considerados teriam sido menores, estimulando o desenvolvimento da atividade e contribuindo para o aumento da renda do produtor. Além disso, a eliminação ou a redução de alíquotas que incidem sobre os insumos favoreceria a competitividade do palmito de pupunha e, consequentemente, as exportações nacionais.

No Espírito Santo, os insumos comercializáveis, ou seja, fertilizantes, defensivos e adubos, representaram $73 \%$ dos gastos com o cultivo do palmito, e em São Paulo, 75\% (AGRIANUAL, 2008; CEDAGRO, 2007). O elevado custo dos 
insumos comercializáveis foi diretamente influenciado pela quantidade e pelo preço. Os fertilizantes, defensivos e adubos são de fundamental necessidade, pois aumentam a produtividade e reduzem o tempo de colheita do palmito, por isso são utilizados em grande quantidade (YUYAMA et al., 2005). Com a redução de impostos sobre esses insumos, os custos se reduziriam e a lucratividade aumentaria, favorecendo a produção do palmito de pupunha.

As transferências associadas aos fatores domésticos no Espírito Santo e em São Paulo foram de R\$ 0,22/kg e R\$ 0,18/ kg, respectivamente. Esses valores positivos indicam custos privados maiores que custos sociais dos fatores domésticos. Em outras palavras, representam uma transferência negativa para o setor produtivo, uma vez que contribuíram para a redução do lucro privado.

São Paulo apresentou menor valor de transferência, o que indica menor divergência entre custos privados e sociais dos fatores domésticos e mostra maior eficiência no uso dos fatores domésticos nesse estado.

\subsection{Transferências financeiras associadas à lucratividade (Transferências líquidas)}

A transferência líquida é a soma de todas as diferenças que fazem com que os lucros privados divirjam dos benefícios sociais. Essa medida de transferência é o resultado principal da MAP, pois esse valor mostra a extensão de ineficiência de um sistema agrícola de produção ou de uma região (MOSS, 2006).

Nas duas regiões analisadas, as transferências líquidas foram negativas, indicando que o produtor foi penalizado - são elas: $\mathrm{R} \$ 1,40 / \mathrm{kg}$ e R $\$ 3,43 / \mathrm{kg}$, no Espírito Santo e em São Paulo, respectivamente.

Esses resultados indicam que os produtores de palmito de pupunha tiveram lucros reduzidos, o que pode estar relacionado com taxações impostas à produção e à comercialização do palmito de pupunha, apesar de serem regiões que operam com lucro.

Verificou-se que a produção em São Paulo apresentou transferências maiores, indicando que os produtores desse estado foram mais penalizados por políticas públicas distorcivas.

A produção no Espírito Santo apresentou menor transferência líquida. Isso pode estar relacionado aos custos sociais mais elevados, o que resultou em menor lucro social, daí a menor transferência, e não por ser o sistema menos afetado por políticas distorcivas.

A lucratividade privada é um indicador importante para que o produtor se sinta estimulado a produzir. Para que isso ocorra, é necessário que o governo proporcione melhores alternativas de políticas, como as reduções nas taxações incidentes tanto sobre o produto quanto sobre os insumos usados na produção (MOSS, 2006), que teriam como consequência o aumento da lucratividade e posterior competitividade do palmito de pupunha. 


\subsection{Indicadores de competitividade privados e sociais}

A Tabela 3 mostra os valores privados e sociais gerados pela MAP para os estados analisados. Com os resultados obtidos, verificou-se que a razão custo privado (RCP) da produção do palmito de pupunha em São Paulo apresenta maior competitividade que no Espírito Santo. Entretanto, como a RCP é menor que um em todos os sistemas analisados, considera-se que os mesmos são lucrativos e são remunerados acima do seu retorno normal. Sendo assim, em São Paulo, apenas 34\% do valor adicionado, ou seja, da diferença entre receita e custo dos insumos comercializáveis, a valores privados, é requerido para pagar os fatores domésticos e produzir um quilo a mais do palmito de pupunha por hectare para consumo doméstico. Raciocínio análogo pode ser feito para o Espírito Santo. Apenas $48 \%$ do valor adicionado a valores privados é requerido para pagar os fatores domésticos e produzir um quilo a mais do palmito de pupunha por hectare para consumo doméstico (Tabela 3). Desse modo, esses setores produtivos podem manter os níveis de utilização dos fatores domésticos e, assim, progredir nessa atividade.

Os coeficientes de proteção nominal sobre produtos comercializáveis (CPNp) foram 0,94 e 0,76 no Espírito Santo e em São Paulo, respectivamente. Como os valores encontrados foram menores que a unidade, há desproteção à atividade, uma vez que o produtor do palmito de pupunha recebe um preço interno menor que o internacional. Além disso, esses resultados mostram que existem taxações implícitas sobre os sistemas de produção do palmito de pupunha resultantes das medidas de políticas, uma vez que seus preços se encontram abaixo dos internacionais, o que levou produtores do Espírito Santo e de São Paulo a receber, respectivamente, $6 \%$ e $24 \%$ a menos do que os preços praticados no mercado internacional (Tabela 3).

Tabela 3. Indicadores de competitividade privados e sociais gerados pela MAP no Espírito Santo e São Paulo, março de 2009.

\begin{tabular}{ccc}
\hline Indicadores & Espírito Santo & São Paulo \\
\hline RCP & 0,48 & 0,34 \\
CRD & 0,33 & 0,16 \\
CPN & 0,94 & 0,76 \\
CPNp & 0,94 & 0,76 \\
CPNi & 1,12 & 1,27 \\
CPE & 0,77 & 0,53 \\
CL & 0,60 & 0,42 \\
TSP & $-0,14$ & $-0,34$ \\
\hline
\end{tabular}

Fonte: Dados da Pesquisa. 
Como os resultados encontrados para o coeficiente de proteção nominal sobre insumos comercializáveis (CNPi) foram maiores que um nos dois estados considerados, observou-se que há transferências negativas de $12 \%$ e $27 \%$ no Espírito Santo e em São Paulo, respectivamente, pois os custos dos insumos comercializáveis são aumentados pela intervenção política. Os valores do CNPi mostram, ainda, que os produtores do palmito de pupunha de São Paulo receberam taxação mais alta devido a essas políticas distorcivas praticado no setor (Tabela 3).

Os coeficientes de proteção efetiva (CPE) para o Espírito Santo e São Paulo foram, respectivamente, de 0,77 e 0,53, ou seja, os valores foram menores que um, indicando elevada desproteção ou taxação no setor produtivo do palmito de pupunha nesses estados. Isso demonstra que o setor foi penalizado por políticas públicas distorcivas (Tabela 3).

O fato de São Paulo ter apresentado menor CPE pode estar relacionado com o menor preço dos adubos, fertilizantes e defensivos nesse estado, em comparação com o Espírito Santo. O cultivo da pupunheira para palmito é bastante exigente no uso de fertilizantes para maximizar a produção e aumentar a vida útil do cultivo, conforme mencionou Bovi (2000). Assim, o menor preço dos adubos, fertilizantes e defensivos pode estar proporcionando uma redução dos efeitos negativos de políticas com a redução dos custos.

Os coeficientes de lucratividade (CL) encontrados neste estudo foram menores que um, o que significa que a produção do palmito de pupunha foi liquidamente taxada e que o lucro privado se reduziu. Significa, também, desproteção total da produção do palmito de pupunha no Brasil (Tabela 3).

A taxa de subsídios aos produtores (TSP) indica que os dois estados analisados sofreram alguma taxação, por apresentarem valores negativos. Os valores encontrados indicam que o Espírito Santo e São Paulo foram taxados ou tiveram suas receitas reduzidas, respectivamente, em 14\% e 34\% (Tabela 3).

\subsection{Análise de Sensibilidade}

Os efeitos de um acréscimo de $10 \%$ nos preços sociais sobre os indicadores privados e sociais da MAP estão apresentados na Tabela 4, o que mostra que a RCP não se alterou com o aumento de $10 \%$ nos preços sociais. Esse resultado era esperado, pois o indicador é formado por variáveis que não dependem do fator de conversão. Consequentemente, variações nos fatores não comprometem a competitividade do palmito de pupunha nos dois estados produtores analisados.

$\mathrm{O}$ valor do CRD não se alterou com a variação nos preços sociais. Assim, a eficiência produtiva e a vantagem competitiva desse sistema de produção permaneceram as mesmas. 
Tabela 4. Análise da sensibilidade dos indicadores da MAP, dada uma variação de $10 \%$ nos preços sociais, para a produção do palmito de pupunha no Espírito Santo e São Paulo, março de 2009.

\begin{tabular}{ccc}
\hline Indicadores & Espírito Santo & São Paulo \\
\hline RCP & 0,48 & 0,34 \\
CRD & 0,33 & 0,16 \\
CPN & 0,86 & 0,69 \\
CPNp & 0,86 & 0,69 \\
CPNi & 1,02 & 1,16 \\
CPE & 0,70 & 0,49 \\
CL & 0,55 & 0,38 \\
TSP & $-0,16$ & $-0,36$ \\
\hline
\end{tabular}

Fonte: Dados da pesquisa.

Os indicadores CPN e CPNp tiveram redução de 7\% e 8\%, respectivamente, em São Paulo e Espírito Santo, resultante do acréscimo de $10 \%$ nos preços sociais. O CPNi apresentou redução média de $10 \%$ nos estados analisados em virtude da alteração nos preços sociais. Como tais valores permaneceram maiores que a unidade, há transferência de renda de produtores para a sociedade.

Em decorrência do aumento de $10 \%$ nos preços sociais, o CPE foi reduzido $4 \%$ e 7\%, respectivamente, em São Paulo e no Espírito Santo. Esses resultados apontam aumento na taxação ou desproteção à atividade, uma vez que a diferença entre o preço no mercado internacional (valoração social) e o preço interno (preço privado) aumentou, podendo-se afirmar que as políticas praticadas penalizaram o setor produtivo do palmito de pupunha.

No tocante ao indicador CL, verifica-se que os valores diminuíram $4 \%$ e 5\%, respectivamente, em São Paulo e Espírito Santo, em virtude de os preços sociais terem aumentado $10 \%$. Esse resultado indica decréscimo do lucro privado em relação ao benefício social. Então, pode-se concluir que o incremento no preço social elevou a desproteção da produção do palmito de pupunha nos estados em questão. Os resultados encontrados pelo indicador TSP também confirmam que houve elevação da taxação na produção do palmito de pupunha no Espírito Santo e em São Paulo, proveniente do acréscimo de $10 \%$ nos preços sociais.

Sintetizando, a análise de sensibilidade pelo incremento nos preços sociais indica que falhas no processo de obtenção dos preços podem esconder os efeitos negativos das políticas adotadas no setor produtivo do palmito de pupunha, visto que o aumento nos preços sociais gerou aumento da desproteção e taxação do setor. 


\section{Conclusões}

Os resultados do trabalho permitem concluir que a lucratividade privada e a social da produção e comercialização do palmito de pupunha foram positivas no Espírito Santo e em São Paulo. Entre esses estados, São Paulo apresentou lucratividade maior, que pode estar associada à maior produtividade e a menores custos com insumos comercializáveis e fatores domésticos. Em média, esses custos são 34,02\% menores em São Paulo se comparados com os do Espírito Santo. Esses fatores fazem com que o estado de São Paulo seja mais competitivo na produção de palmito e menos exposto aos efeitos negativos das políticas públicas.

A cultura do palmito de pupunha no Espírito Santo e em São Paulo é lucrativa e competitiva, porém vem sendo prejudicada com a implantação de políticas públicas distorcivas, conforme indicado pelo fato de os coeficientes de proteção nominal sobre produtos comercializáveis, de proteção efetiva e de lucratividade serem menores que a unidade, e pelo fato de os coeficientes de proteção nominal sobre insumos comercializáveis serem maiores que a unidade e as taxas de subsídios apresentarem valores negativos. Do contrário, produtores brasileiros poderiam ter alcançado níveis mais altos de lucratividade e competitividade.

Para melhorar a competitividade e a lucratividade do palmito de pupunha no País, algumas medidas de políticas podem ser implantadas, como redução de impostos que incidem sobre a produção, bem como taxas de juros nos financiamentos e encargos trabalhistas que sobrecarregam os custos de produção. As mudanças tecnológicas também têm efeito positivo na competitividade e na lucratividade brasileira do palmito de pupunha.

No médio prazo, a reorientação nas medidas de políticas poderia favorecer produtores e consumidores do palmito de pupunha, resultando em maior incentivo à produção.

Ressalta-se que a principal limitação para o desenvolvimento deste trabalho foi a falta de informações precisas sobre o setor que produz palmito de pupunha no Brasil.

\section{Referências Bibliográficas}

AGRIANUAL. Anuário estatístico da agricultura brasileira. São Paulo: FNP Consultoria e Comércio, 2008.

AGRIANUAL. Anuário estatístico da agricultura brasileira. São Paulo: FNP Consultoria \& Comércio, 2009. 495 p.

AHMAD, S.; MARTINI, R. P. Agricultural Policy Analysis in Pakistan: Illustrations in the use of the Policy Analysis Matrix. Working Paper, 2000. 
ALVES, J. M. Competitividade e tendência da produção de manga para exportação do nordeste do Brasil. Piracicaba, SP: ESALQ/USP, 2002. 163 f. Tese (Doutorado em Ciências: Área de Concentração - Economia Aplicada) - Escola Superior de Agricultura "Luiz de Queiroz", Universidade de São Paulo, Piracicaba.

ALVIM, M. I. da; OLIVEIRA JÚNIOR, L. B. de. Análise da competitividade da produção de soja no sistema de plantio direto no Estado de Mato Grosso do Sul. Revista de Economia e Sociologia Rural. Rio de Janeiro, v.43, n.3, p.505-528, jul. / set. 2005.

ALVIM, M. I. da; VALLE, S. M. L. R. do; LIMA, J. E.; SILVA, O. M. da. Análise da competitividade da produção de soja nos sistemas de plantio direto e plantio convencional na região do Cerrado Brasileiro. Revista de Economia e Sociologia Rural. Rio de Janeiro, v.42, n.2, p.223-242, abr. / jun. 2004.

BOVI, M. L. A. O agronegócio palmito de pupunha. O Agronômico, Campinas, 52(1), 2000.

CENTRO DE DESENVOLVIMENTO DO AGRONEGÓCIO - CEDAGRO. Coeficientes técnicos. Disponível em: < http://www.cedagro.org.br> Acesso em: 14/06/2008.

CENTRO DE INTELIGÊNCIA EM FLORESTAS - CI Florestas. Mercado internacional. Disponível em: <http://www.ciflorestas.com.br/dados. php $\mathrm{id}=99 \& \mathrm{n}=$ mercado_internacional $>$.

Acesso em: 15/04/2010.

CHAIMSOHN, F.P. Cultivo de pupunha e produção de palmito. Viçosa: Aprenda Fácil, 2000. 121p.

CHAIMSOHN, F. P. Producción y calidad del palmito al natural, em función de la población, del arreglo de plantas y del tipo de fertilización. Costa Rica: UCR, 2006. 205 f. Tese (Doutorado em Sistema de produção agrícola tropical sustentável, Universidad de Costa Rica., Costa Rica.

DELEPINASSE, B. M.; BONSE, R. Diagnóstico da comercialização de produtos florestais. Brasília: Ministério do Meio Ambiente, 2002. 205 p.

ENDOM, M. A. Economic Analysis of Large Scale Logging. Working Paper, nº 3, 1999. Disponível em: < http://www.worldagroforestry.org/sea/Publications/files/ workingpaper/WP0021-04.PDF>. Acesso em: 07/07/2008.

FERREIRA NETO, J. Competitividade da produção de cana-de-açúcar no Brasil. Viçosa, MG: UFV, 2005. 87 f. Dissertação (Mestrado em Economia Aplicada) Universidade Federal de Viçosa, Viçosa.

GUERREIRO, L. F. Palmito de Pupunha. (2002). Disponível em: www.desenbahia. ba.gov.br. Acesso em: 30/04/2009. 
HADI, P. U.; BUDHI, G. S. Analysis of the Economic Efficiency and Comparative Advantage of the Sumatran Smallholder Rubber Using "PAM" Method. Working Paper, no. 4, 1997. Disponível em: <http://www.worldagroforestrycenter.org/sea/ Publications/files/workingpaper/WP0022-04.PDF>. Acesso em 22/08/2008.

HAGUENAUER, L. Competitividade: conceitos e medidas: uma resenha bibliográfica recente com ênfase no caso brasileiro. Texto para Discussão, nº. 211, 20 p., Agosto/1989. Universidade Federal do Rio de Janeiro - Instituto de Economia Industrial.

IE/UNICAMP - IEI/UFRJ - FDC - FUNCEX. Estudo da competitividade da indústria brasileira. Sistema de indicadores da competitividade. Nota Técnica, Campinas, 202 p., 1993.

INSTITUTO BRASILEIRO DE GEOGRAFIA E ESTATÍSTICA - IBGE. Banco de Dados Agregados. Disponível em: http://www.sidra.ibge.gov.br. Acesso em: 13/04/2009.

INSTITUTO BRASILEIRO DE GEOGRAFIA E ESTATÍSTICA - IBGE. Produção Agrícola Municipal. Rio de Janeiro: IBGE, v. 34, 2007. 68p.

INSTITUTO BRASILEIRO DE GEOGRAFIA E ESTATÍSTICA - IBGE. Produção Agrícola Municipal. Rio de Janeiro: IBGE, v. 35, 2008. 91p.

INSTITUTO DE ECONOMIA AGRÍCOLA - IEA. Estatísticas. (2009). Disponível em: http://www.iea.sp.gov.br. Acesso em: 05/01/2009.

INSTITUTO DE PESQUISA ECONÔMICA APLICADA - IPEA. Disponível em: http://www.ipeadata.gov.br. Acesso em: 13/04/2009.

MARRA, R.; MOTA, M. M.; LIMA FILHO, J. R. de; TEIXEIRA, S. M. Cadeia produtiva do café em Minas Gerais. In.: VIEIRA, R. C. M. T.; TEIXEIRA FILHO, A. R.; OLIVEIRA, A. J. de; LOPES, M. R. Cadeias Produtivas no Brasil: análise da competitividade. Brasília: Embrapa Comunicação para transferência tecnológica. Secretaria de Administração Estratégica, 2001, cap. 6, p. 139- 154.

MARTINS, P. C. Efeitos de políticas públicas sobre a cadeia produtiva do leite em pó. In.: VIEIRA, R. C. M. T.; TEIXEIRA FILHO, A. R.; OLIVEIRA, A. J. de; LOPES, M. R. Cadeias Produtivas no Brasil: análise da competitividade. Brasília: Embrapa Comunicação para transferência tecnológica. Secretaria de Administração Estratégica, 2001, cap. 10, p. 241- 272.

MARYANI, R; IRAWANTI, S. Economics analysis of land use system for Large scale plantations of oil palm and industrial timber estate. Working Paper, no. 2, 1997. Disponível em: http://www.worldagroforestry.org/Sea/Publications/files/ workingpaper/WP002004.pdf> . Acesso em: 07/07/2008.

MERECÍ, K. Palmito. 2008. Disponível em: http//:www.mailxmail.com. Acesso em: 3/02/2009. 
MINISTERIO DE AGRICULTURA GANADERÍA, ACUACULTURA Y PESCA DEL ECUADO - SERVICIO DE INFORMACIÓN Y CENSO AGROPECUARIO (SICA). Ecuador: Precio de los Principales Insumos Agrícolas. Disponível em: http:// www.sica.gov.ec/agro/insumos/Boletin_insumos.htm. Acesso em: 12/02/2009.

MINISTÉRIO DO DESENVOLVIMENTO, INDÚSTRIA E COMÉRCIO EXTERIOR - MDIC. Disponível em: < http://www.mdic.gov.br > Acesso em: 15/04/2010.

MOHANTY, S.; FANG, C.; CHAUDHARY, J. Assessing the Competitiveness of Indian Cotton Production: A Policy Analysis Matrix Approach. Working Paper, 2002. Disponível em: < http://www.card.iastate.edu/publications/DBS/ PDFFiles/02wp301.pdf > . Acesso em: 08/07/2008.

MONKE, A.E.; PEARSON, S.R. The policy analysis matrix for agricultural development. New York: Cornell University Press, 1989. 278p.

MOSS, S. R. Competitividade da produção do café arábica em Minas Gerais e São Paulo. Viçosa, MG: UFV, 2006. 90 f. Dissertação (Mestrado em Economia Aplicada) Universidade Federal de Viçosa, Viçosa.

NELSON, A. W. Applications of the Policy Analysis Matrix (PAM). Working Paper, 1991. Disponível em: < http://www.ifpri.org/training/material/miscellaneous/ Foodpolicycom/AppendixF_policymemoranda.pdf $>$. Acesso em: 08/07/2008.

NELSON, C.G.; PANGGABEAN, M. The Costs of Indonesian Sugar Policy: A Policy Analysis Matrix Approach. American Journal of Agricultural Economics, v. 73, p. 703-12, 1991.

REZENDE, J. L. P. de; OLIVEIRA, A. D. de; RODRIGUES, C. Efeito dos tributos no custo de produção, na rotação e na reforma de Eucalyptus spp. Revista Cerne, Lavras, v. 11, n. 1, p. 70-83, jan./mar. 2005.

ROSADO, P. L. Competitividade e expansão da avicultura e suinocultura no contexto do MERCOSUL. Viçosa, MG: UFV, 1997. 105 f. Dissertação (Mestrado em Economia Rural) - Universidade Federal de Viçosa, Viçosa.

ROSADO, P. L.; TOSTO, S. G.; GOMES, M. F. M. Competitividade e expansão da produção de borracha natural brasileira, no contexto de liberalização dos mercados. In.: ALVARENGA, A. P.; ROSADO, P. L.; CARMO, C. A. F. S. De; TOSTO, S. G. Seringueira: Aspectos Econômicos Sociais e Perspectivas para o seu Fortalecimento. Viçosa, MG; 2006. cap. 6, p. 103 - 128.

SAMPAIO, L. C.; NETO, S. N. O.; LELES, P. S. S.; SILVA, J. A.; VILLA E. B. Análise técnica e econômica da produção de palmito de pupunha (Bactris gasipaes Kunth.) e de palmeira real (Archontophoenix alexandrae Wendl. \& Drude). Revista Floresta e Ambiente. v. 14, n. 1, 2007. 
STCP ENGENHARIA DE PROJETOS. DISPONÍVEL EM: http://www.stcp.com.br/. Acesso em 06/05/2010.

VERRUMA-BERNARDI, M. R.; MORAES, C. W. S. de; MACHADO, C. A.; KAJISHIMA S.; COSTA, E. Q. Análise descritiva quantitativa do palmito de pupunheira. Acta Amazonica, v. 37, n. 4, 2007.

VIEIRA, R. C. M. T.; TEIXEIRA FILHO, A. R.; OLIVEIRA, A. J. de; LOPES, M. R. Cadeias Produtivas no Brasil - Análise da Competitividade. Revista de Política Agrícola. Ano X, n. 4, p. 7 -15, out./dez. 2001.

VILLACHICA, H. 1996. Cultivo del pijuayo (Bactris gasipaes Kunth.) para palmito en la Amazonia. Lima, Peru: FAO/Tratado de Cooperacion Amazonica, 153 p.

YUYAMA, K.; CHÁVEZ F., W.B.; PEREIRA, B.G.; SILVA, I.A. Efeito da densidade de plantas e da adubação NPK na produção inicial de palmito de pupunheira. Revista Brasileira de Ciência do Solo, Viçosa, V. 29, p. 373-378, 2005. 